\title{
Applying an Information Problem- solving Model to Academic Reference Work: Findings and Implications
}

\section{Janet R. Cottrell and Michael B. Eisenberg}

The usefulness of the Eisenberg-Berkowitz Information Problem-Solving model as a useful categorization for academic reference encounters is examined. Major trends in the data include a high proportion of questions about location and access of sources, a lack of synthesis or production activities, and a consistent presence of system problems (such as hardware problems) that impede the information-seeking process. The implications of these trends for the reference process, librarian training, and campus organization are discussed.

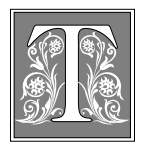
he rapid and prolific introduction of electronic resources poses new challenges for academic reference desks. To help meet these challenges, new ways of looking at the reference process may help. Traditionally, reference encounters have been considered in terms of the type of question or the type of patron involved. Recently, however, the reference encounter has been considered more fully as a process. After reviewing both models, this study examines the usefulness of one specific model in the reference processthe Eisenberg-Berkowitz Information Problem-Solving (IPS) model.

\section{Characteristics of Reference Questions}

Much of the existing literature on characterizing reference encounters focuses on categorizing type of patron or type of question. Although clientele in the aca- demic reference environment are not altogether homogeneous, most patrons are affiliated with the university in one way or another. However, the variety in questions is almost endless; in response, researchers have devised ways to characterize them. Richard L. Derr categorized questions based on their conceptual presupposition: ${ }^{1}$

- Existence (Does X exist?)

- Identity (What is X? Who is $X$ ?)

- Properties (What are the features of $X$ ?)

- Relation (How is $X$ related to $Y$ ?)

- Number (How many of $X$ are there?)

- Location (Where is $\mathrm{X}$ ?)

- Time (When is $X$ ?)

- Action (What is X doing?)

Although this categorization offers an illuminating look at types of factual questions, it does not apply well to other types of questions encountered at an aca-

Janet R. Cottrell is Director of Information Access, Library and Information Services, at Kenyon College; e-mail: cottrellj@kenyon.edu. Michael B. Eisenberg is a Director and Professor in the Information School at the University of Washington; e-mail: mbe@u.washington.edu. 
demic reference desk. Richard E. Bopp described several types of reference services: ${ }^{2}$

- Ready reference: Ready reference questions are answered quickly by consulting one or two standard tools.

- Bibliographic verification: Facts about publications are used to find or retrieve the publications.

- Interlibrary loans and document delivery: This involves the verification of bibliographic information preparatory to interlibrary lending.

- Information and referral services: These services involve the identification of community resources and agencies that can respond to a query.

- Research questions: Research questions reflect broader user needs and are more complex than ready reference questions. They require more effort and careful review and may take place over time.

- Selective dissemination of information: This service involves ongoing notification and keeps researchers abreast of current developments in their fields.

- Database searches: This is mediated searching, often by appointment, away from the desk.

F. Wilfrid Lancaster and Amy J. Warner used a somewhat similar scheme to characterize reference encounters, categorizing information needs by purpose and scope. ${ }^{3}$ They proposed two types of information need: the need to locate and obtain a copy of a particular document for which the author or title is known ("known-item need"); and the need to locate documents that are on a particular subject or are capable of answering a particular question ("document delivery capability"). In addition, they identified three types of retrospective search: the need for a single item of factual data (ready reference); the need for one or more documents on a subject (but less than the total literature); and the need for a comprehensive search in which as much of the literature as possible on a subject is retrieved during a period of time.

Other researchers have focused on the complexity or difficulty of questions ac- tually recorded at reference desks, as well as the type of question or answer. Diane $\mathrm{M}$. Brown analyzed telephone reference questions to characterize them by Dewey Decimal subject, answer format, and level of complexity as indicated by the specificity of the sources consulted. ${ }^{4}$ Thomas Childers, Cynthia Lopata, and Brian Stafford studied reference questions looking for a measure of different levels of difficulty and indicative measures to stand for the concept of difficulty. ${ }^{5}$

\section{Characteristics of the Reference Process}

Studies such as those mentioned above are interesting from a theoretical and statistical point of view, but in the midst of a demanding desk shift, they lose some of their appeal. More important, they place their emphasis on the question itself; by doing so, they draw attention away from another important aspect of the reference encounter-the process. Particularly in academic reference work, the process assumes great importance because it frequently occurs as part of an undergraduate or graduate student's educational experience. In these encounters, it is not necessarily the patron, the question, or the answer that matters; rather, it is the process by which student and librarian solve an information problem and find information appropriate to the task at hand.

Every basic reference textbook contains information on conducting reference interviews, and many emphasize looking beyond the originally presented question. Ellen D. Sutton and Leslie E. Holt noted that, in fact, the entire interview process can be seen as problem centered rather than question centered. ${ }^{6}$

The emphasis on process rather than question was the basis for work by Carol C. Kuhlthau, who developed a model of the library search process incorporating both cognitive and affective aspects..$^{7-9}$ Based on her studies of students performing library research, Kuhlthau's model included six steps:

1. Initiation: Student receives assignment. 
2. Selection: Student selects general topic area.

3. Exploration: Student explores material on general topic.

4. Formulation: Student focuses on more specific topic.

5. Collection: Student collects materials on focused topic.

6. Presentation: Student prepares and presents finished assignment.

Kuhlthau emphasized three main findings of major importance to librarians:

- Library searching is a process over time and not a single event.

- Library searching is a holistic event rather than a simple activity.

- Library searching commonly initially increases rather than decreases uncertainty.

Kuhlthau recognized that her model had implications for reference practice: reference librarians who have become aware of the stages in the information search process model "listen for an indication of the stage in the process of the user and particularly note when someone is 'in the dip' [of uncertainty] and needs some extra help to formulate a research focus." 10

\section{Both the head of the reference department and the researcher/ librarian agreed from the beginning that because the research relies on the reference process, it must be almost totally unintrusive.}

Lynn Kennedy, Charles Cole, and Susan Carter applied Kuhlthau's model specifically to academic reference work, using a simplified version of it to assess and explicitly label undergraduates' information needs as expressed at the reference desk and then designing appropriate search strategies for each phase. ${ }^{11}$ They first reduced Kuhlthau's model to three stages: the Pre-Focus stage, in which the student selects a topic and locates general information (Kuhlthau's stages 1,2, and 3); the Semi-Focus stage, in which the student chooses a specific focus from the background information (Kuhlthau's stage 4); and the Post-Focus stage, where the student gathers specific information to prove or disprove the thesis and presents the findings (Kuhlthau's stages 5 and 6). Reasoning that explicitly labeling these stages would help identify the actual information need, Kennedy, Cole, and Carter next determined appropriate search strategies for each stage: high-recall searches for the Pre-Focus stage, high-recall/high-precision searches for the Semi-Focus stage, and high-precision searches for the PostFocus stage. This groundbreaking research illustrates the utility that information-processing models can have in reference work.

\section{Eisenberg-Berkowitz Model}

Michael B. Eisenberg and Robert E. Berkowitz describe a six-stage model of Information Problem-Solving (IPS) ${ }^{12} \mathrm{At}$ its most general level, the IPS model simply asserts that whenever students are faced with an information problem (or with making any decision that is based on information), they can use a systematic, problem-solving process. At its more detailed levels, the model includes six stages in the information problem-solving process, each having two specific components:

1. Task Definition

1.1 Define the problem.

1.2 Identify the information requirements of the problem.

2. Information-seeking Strategies

2.1 Determine the range of possible sources (brainstorm).

2.2 Evaluate the different possible sources to determine priorities.

3. Location and Access

3.1 Locate sources (intellectually and physically).

3.2 Find information within sources.

4. Use of Information

4.1 Engage (read, see, hear) the information in a source.

4.2 Extract relevant information from a source.

5. Synthesis 
5.1 Organize information from multiple sources.

5.2 Present information.

6. Evaluation

6.1 Judge the product (effectiveness).

6.2 Judge the information problemsolving process (efficiency).

Although its stages often occur in the order listed, the model allows jumping between stages or looping back to previous steps as needed.

Colloquially called the Big Six because of its six steps, this model has been widely adopted in education circles; the $\mathrm{K}-12$ information literacy standards for many states are based on it. As more and more colleges and universities develop information literacy competencies, academic librarians also are becoming familiar with its potential (see Mary Warner for an example ${ }^{13}$ ).

Considering the Eisenberg-Berkowitz model in the academic reference setting suggests the following research questions:

- Can academic reference encounters be characterized using the Eisenberg-Berkowitz IPS model? Do they fit gracefully?

- Can the IPS model tell anything about how to approach the encounters, in terms of both answering the question and helping the client? If so, what implications does this have?

The remainder of this paper describes an attempt to study these questions.

\section{Methods}

\section{Collection and Coding of Data Sets}

Two sets of data were collected and used in this study. The first set consists of brief descriptions of 170 reference encounters at a midsize state university's main library. The encounters took place during a weekly 2.5- to 3-hour midday, midweek desk shift over the course of one semester. The reference librarian jotted down very brief notes during the shift, then expanded them as soon as possible after the shift ended. The first fifty descriptions were examined to see whether they could be characterized in terms of the compo- nents of the Eisenberg-Berkowitz model. Consultation with the model's codeveloper helped clarify questions about how to code certain types of encounters. ${ }^{14}$ The remaining descriptions were then coded, and the entire set of 170 encounters was treated as one preliminary data set.

The second data set consists of brief descriptions of another 123 reference encounters from the following semester. These encounters were recorded and coded according to the methodologies developed with the first set.

The second set of data was collected in an attempt to refine and verify the earlier set. However, the constraints operating during the first phase were still operating during the second phase, so the methodology did not change substantially. In addition, some characteristics of the reference area (including database assortment and printing procedures) changed substantially during the interval between the two collection periods. The data from the two phases were therefore analyzed and reported separately.

\section{Constraints on Data Collection}

Because the data result from reference encounters in a university library, great care was taken during data collection. Both the head of the reference department and the researcher/librarian agreed from the beginning that because the research relies on the reference process, it must be almost totally unintrusive. In other words, the reference process itself must always take precedence over the needs of the researcher. This placed severe constraints on the research process, especially during data collection.

Constraints on the data collection include:

- cannot elicit certain types of data (patron status, age, affiliation, other demographics; too invasive);

- cannot have an external observer or machine recording the encounters (unethical to tape without consent; impossible to observe session closely without being in the way); 
- cannot take extensive notes during the encounters or between encounters (too intrusive during encounter; no time between encounters);

- cannot have a checklist visible to the patron (too intrusive/disruptive to patron).

The compromise was that the researcher/librarian carried a small pad and jotted down a few keywords during or right after encounter. Often the researcher/librarian would do this anyway (for example, to jot down search terms while working on a search with a patron), so this activity was considered part of the ordinary reference process.

Clearly, this meant that the researcher/librarian must reconstruct the encounters from memory, using the brief notes jotted down during the encounter. The goal was to do this as soon as possible after the end of the shift; occasionally, this was not possible and some time elapsed between the encounter and the summarization.

One additional requirement was always enforced on data collection: must record all encounters during the shift, not just the memorable ones. This requirement is essential to compiling a fully representative data set, even though it demands a strong commitment on the part of the librarian and may limit the number of data collectors in a full-blown study.

\section{Clarification of Coding}

Guidelines were needed to promote consistent coding of the encounters. The following list, developed as a preliminary coding aid, includes brief definitions of each component from Eisenberg and Berkowitz, then identifies behaviors specific to the academic reference setting. ${ }^{15}$

1. Task Definition

1.1 Define problem.

Determining what is required for an assignment, outlining tasks, determining order. Behaviors specific to the academic reference environment might include:

- consulting the assignment;

- focusing/clarifying the topic (of paper, etc.);
- relaying information about the task to the librarian.

1.2 Identify information requirements of problem.

Realizing specific types of information required for a project. Behaviors specific to the academic reference environment might include:

- discussing assignment or task in terms of:

-number of sources needed;

-type of sources needed (book, journal articles, scholarly, popular, etc.);

-type of information needed (focus, level of detail, information not needed).

2. Information-seeking Strategies

2.1 Determine range of sources.

Brainstorming possible sources of information to meet the requirements. Behaviors specific to the academic reference environment might include:

- discussion about what has been tried already;

- discussion about likely fields (humanities, social sciences, etc.--starting points on main menu);

- discussion about likely indexes to use;

- discussion about likely keywords;

- discussion about potentially useful print sources;

- discussion of appropriate sources (print, Web, etc.).

2.2 Evaluate possible sources to determine priorities.

Deciding which of sources are likely to be most useful. In the academic reference environment, this stage is often rolled in with 2.1; specific behaviors might include:

- picking which database to try first;

- looking through a list of citations to select useful items.

3. Location and Access

3.1 Locate sources intellectually and physically.

Finding sources of information, including specific books, articles, full-text sources, etc. In the academic reference setting, this might include:

- questions about location of specific call numbers, reference books, special collections, etc.; 
- ILL (suggesting ILL, accepting ILL requests for processing).

3.2 Find information within sources.

Behaviors specific to the academic reference environment might include:

- using the index or table of contents in print sources;

- skimming full-text sources online;

- skimming print sources.

4. Use of Information

4.1 Engage.

Using a source to gain information. Behaviors specific to the academic reference environment might include:

- reading full text or Web page online;

- reading print source (atlas, fact book, reference book, etc.);

- obtaining nondirectional facts from reference librarian.

\subsection{Extract}

Taking notes or recording information from a source. In an academic reference environment, this might include:

- taking notes from full-text or print sources;
- printing full-text sources;

- printing Web sites.

5. Synthesis

5.1 Organize information from multiple sources.

Integrating information from a range of sources. In an academic reference environment, this might include:

- discussion of how information from different sources will be used;

- writing a bibliography after comparing formats from more than one style guide.

5.2 Present information.

Creating a product such as a paper, presentation, illustration, final project, etc. This stage is seldom observed in the academic reference setting.

6. Evaluation

6.1 Judge the product (effectiveness).

Determining whether the information need has actually been met effectively, as determined by the final product or project. This step is seldom observed in the academic reference setting because the product has not yet been created.

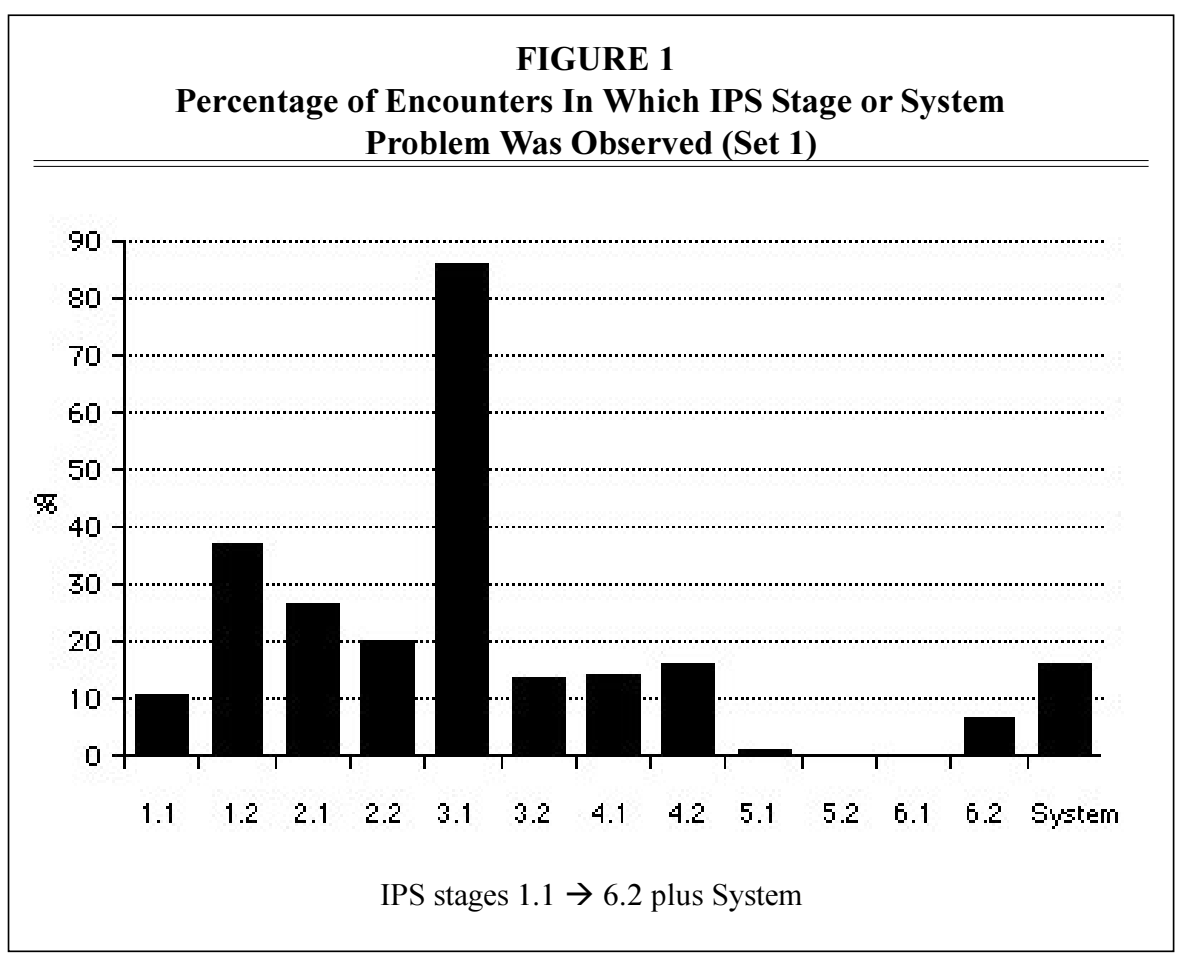




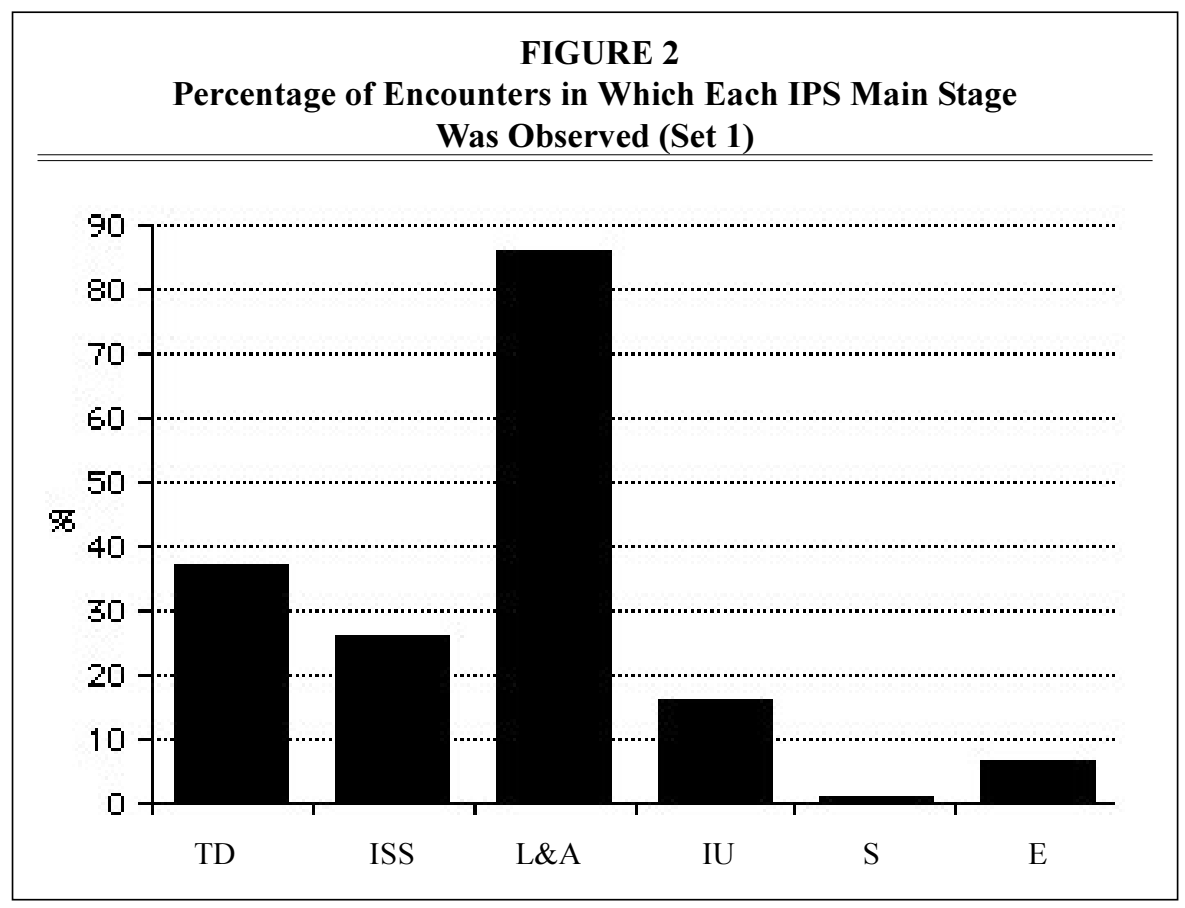

6.2 Judge the IPS process (efficiency).

Determining how well the information problem-solving process worked. In the academic reference setting, this might include:

- periodically evaluating whether useful hits are being found;

- periodically evaluating whether correct database is being used;

- reference librarian asking patron whether useful information is being found.

One additional coding category was developed to deal with problems encountered during reference that were outside the scope of the IPS process. These problems, tentatively labeled "System problems" were often (though not always) hardware problems. They were not stages in the information process but, rather, directly impeded the IPS process, often by preventing access to an information source.

Each encounter was evaluated for any indication of any of the twelve IPS subcomponents plus any indication of system problems. Any given encounter could exhibit any number of the possible coding components.

\section{Results}

For each of the two data sets, the stages observed in each encounter were tallied, along with any system problems. Results were compiled for the number of encounters in which each of the twelve IPS substages (and system problems) were observed and for the total number of stages observed in each encounter. The data sets from the first and second phases are presented separately.

\section{Phase One Data Set}

\section{Frequency of IPS Stages}

Figure 1 shows the percentage of encounters in the first data set (a total of 170 encounters) in which each of the model's twelve substages were observed. The percentage of encounters in which system problems were observed is noted at the far right of figure 1 .

Despite the coding guidelines, there were still some instances in which the coder was unsure how to classify an observation. Often this uncertainty had to do with which substage the observation reflected within the six major steps; in other words, the coder might recognize 
an observation as task definition but be unsure whether to code it as 1.1 or 1.2 . Because the uncertainty was at the substage level and not the main stage level, the data were then collapsed across substages. Figure 2 illustrates the percentage of encounters in which each IPS main stage was observed, regardless of substage coding.

In both figures 1 and 2, the most notable features are the high frequency of location and access observations (step 3 in the model), and the low number of synthesis observations (step 5 in the model).

Nearly 90 percent of all encounters included location and access, primarily characterized by physically or intellectually locating sources (3.1); in fact, 44 percent of all encounters included only stage 3.1 activities. Generally, the stage 3.1 activities included either giving directions for locating call numbers in the stacks, departments of the library, and so on (physical location) or helping patrons find likely sources of information by using indexes, databases, and so on (intellectual location).

Even the two cases in which synthesis was observed were not clear-cut: they represent encounters in which students discussed how they planned to combine information from diverse fields of study in their final product.

As figure 3 shows, more than half the reference encounters in the first phase included just one of the twelve information problem-solving subcomponents. Most of these single-stage encounters involved location and access: 44 percent of all encounters included only stage 3.1 activities.

In some encounters (the "zero" category in figure 3), no IPS components were observed. These cases represent encounters in which only system problems (outside the IPS process) were observed.

\section{System Problems}

As indicated in figure 1, about 16 percent of the encounters in the first phase included system problems, defined during the coding as problems encountered during reference that were outside the scope of the IPS process, often (though not always) hardware problems. System problems were not steps in the IPS process; instead, they impeded the IPS process, typically by preventing access to an information source or extraction of information from a source. Examples of system problems include microcomputer "freeze-ups," server crashes, printer malfunctions, access problems

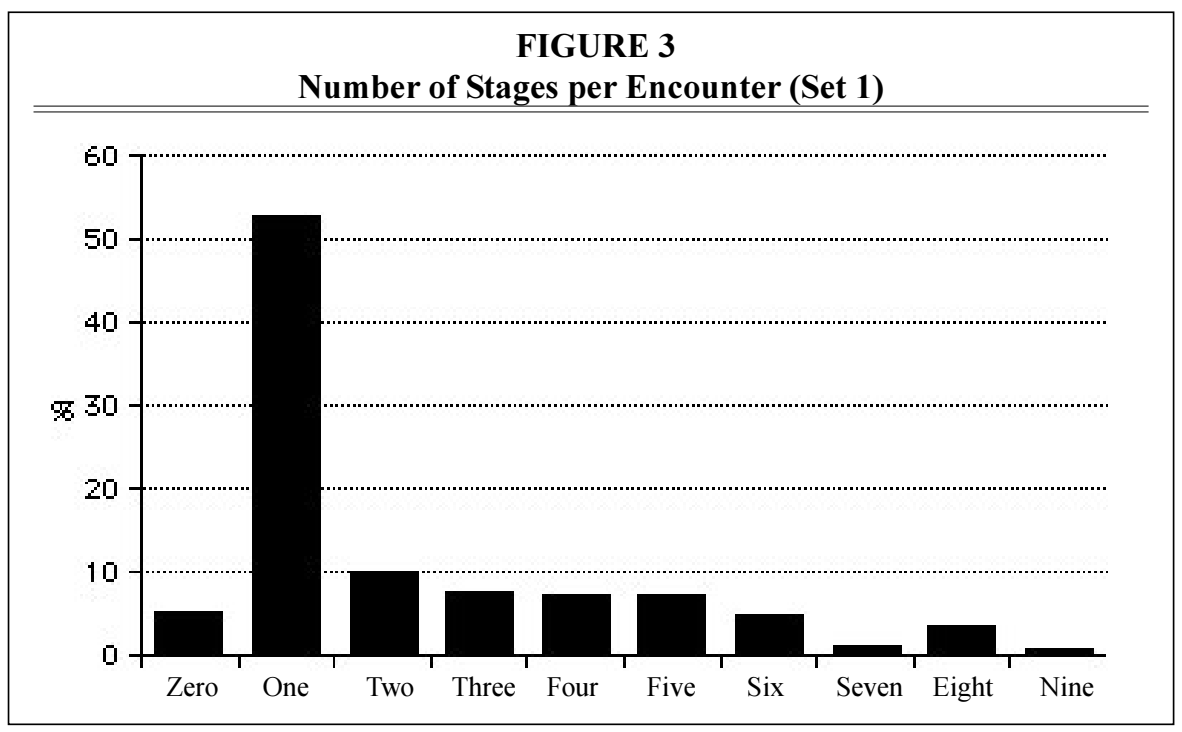




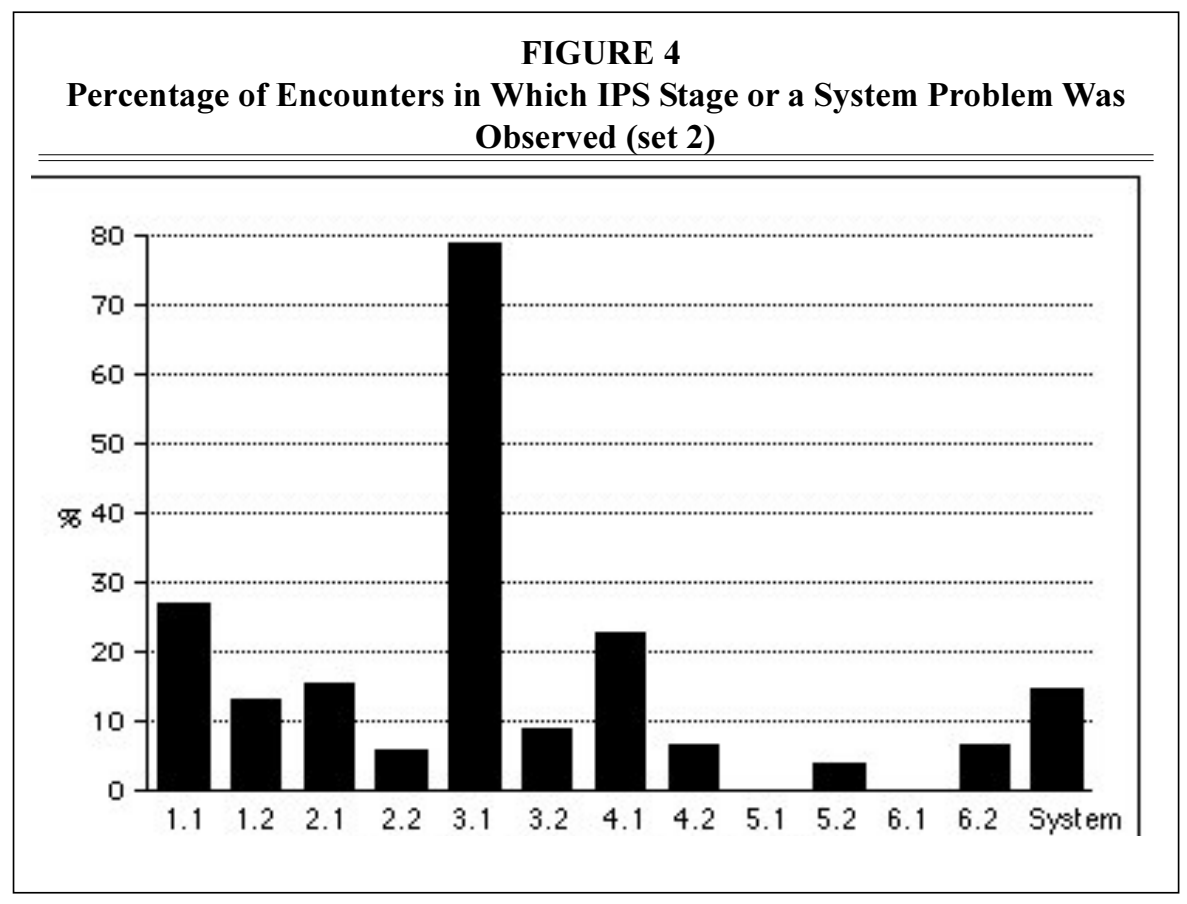

on databases requiring university ID (bar code access), slow or no response from remote databases, and so on. Encounters in which a badly designed user interface impeded the IPS process also were designated system problems. In one case, for example, even the printed instructions for using a specific database provided no clue on how to print the full-text findings.

When the system problem clearly impeded a specific step in the IPS process, both the system problem and the specific IPS stage were coded. For example, the case just described (badly designed interface) was coded as involving a system problem during information extraction (4.2).

\section{Phase Two Data Set \\ Frequency of IPS Stages}

Figure 4 shows the percentage of encounters (out of the total of 123 in the second data set) in which each of the model's twelve substages were observed. The percentage of encounters in which system problems were observed is noted at the far right of the graph.
The data then were collapsed across substages in case of any uncertainty at the substage level. Figure 5 shows the percentage of encounters in which each IPS main stage was observed, regardless of substage coding.

In figures 4 and 5, as in figures 1 and 2, the greatest number of observations are in the location and access stage of the model, and the least number of observations are in the synthesis stage. Nearly 80 percent of the encounters in this data set include location and access activities, primarily the physical or intellectual location of sources (3.1). In fact, 46 percent of all encounters included only stage 3.1 activities of physical or intellectual location.

\section{Number of Stages per Encounter}

As figure 6 indicates, over 60 percent of the reference encounters included just one of the twelve IPS components. Most of these ( $46 \%$ of the total set) involved only stage 3.1 location and access activities.

\section{System Problems}

As figure 4 indicates, about 15 percent of the encounters in the second data set in- 


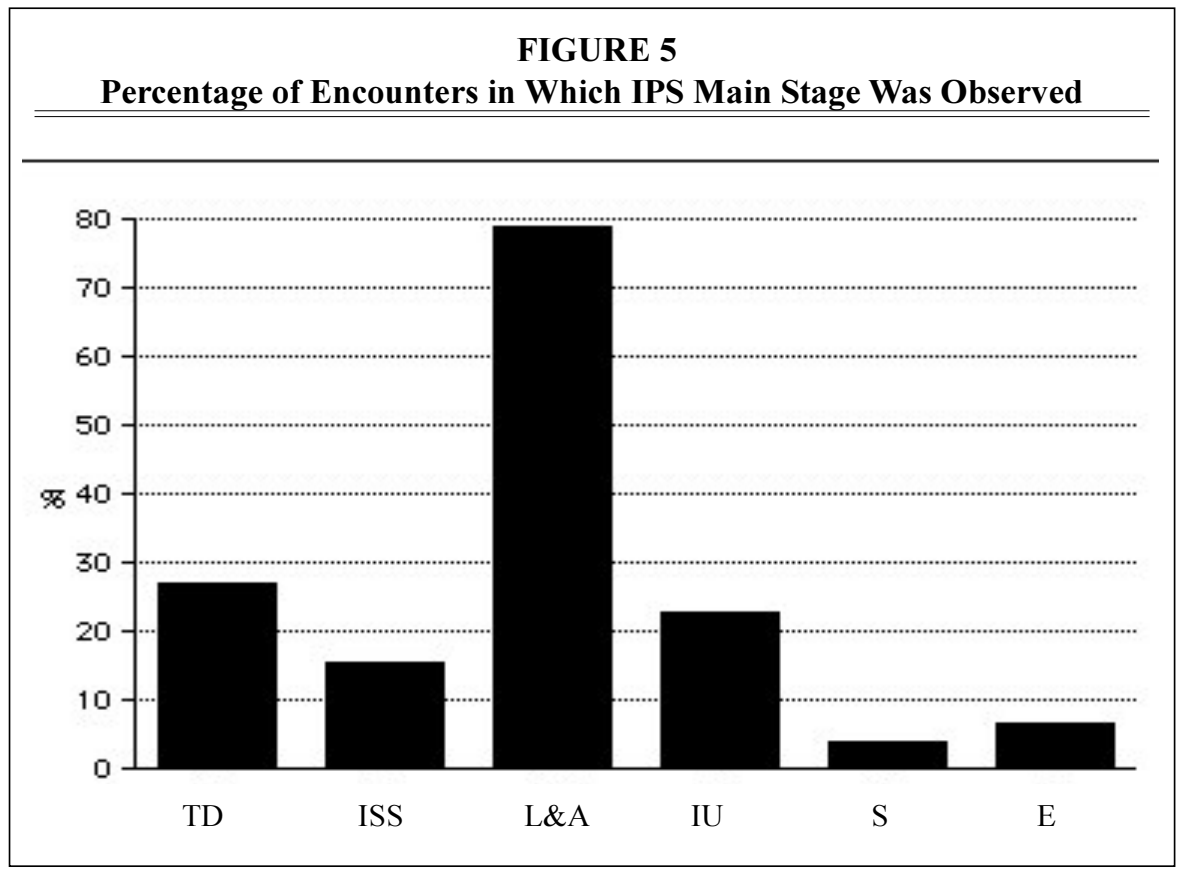

cluded system problems. Because the printing process changed substantially between phases one and two, fewer printing problems occurred. Many of the system problems in this data set concerned IPS-related activities that a patron might reasonably expect to accomplish in the workstation area, which were either not available at all or impeded by lack of a clear interface and instructions. For example, several system problems concerned using campus e-mail software (which is unavailable on these worksta-

Librarians can use the model to ascertain where the student is in the research process, advise accordingly, and verify that all relevant steps are covered.

tions) or registering online for credit courses (which is available but may be blocked by passwords, locks, or other features of the system that may require intervention by other offices such as the registrar or accounting).

As in phase one, when the system problem clearly impeded a specific step in the IPS process, both the system problem and the specific IPS stage were coded. However, if the IPS stage was not clear or relevant (e.g., registering for courses), only the system problem was recorded.

\section{Discussion}

\section{General Findings}

The constraints on data collection did affect the research process. Without the use of an external recorder, detailed notes, or checklists during the actual reference encounter, the description of each encounter was necessarily brief. Even though these brief descriptions were annotated and coded as soon as possible afterward, inevitable delays and incomplete memories affected the quality of the data. Thus, it would be a mistake to overinterpret the current data.

Despite the data collection and coding challenges, the encounters did seem to fit gracefully into the model. Three trends stand out: (1) location and access activities were observed in many encounters; (2) synthesis activities were observed in very few encounters; and (3) 
in many encounters, only one stage of the model was observed. These trends are consistent across both data sets.

These trends are also consistent with what might be expected intuitively. Many of the reference encounters included questions about location and access, and about half the encounters were "one-shot" questions that concerned only one step of the IPS process, primarily location and access. These findings will not surprise many reference librarians, who already feel they spend much of their time giving location directions.

The lack of stage 5 synthesis activities also is not surprising because the workstations in the reference area do not support application software such as word processing, database management, spreadsheet, or graphics packages. As Eisenberg and Doug Johnson pointed out, students often use such tools during synthesis; without the presence of the appropriate tools, the stage is unlikely to be observed. ${ }^{16}$

Librarians in wired academic libraries will not be startled to hear that slightly under 20 percent of the questions revealed "system problems," problems that were outside the scope of the IPS process (usually hardware problems, not information problems) but directly impeded it by preventing access to an information source or extraction of information from a source.

\section{Implications}

Although the results of categorizing academic reference events into the IPS model may be unsurprising, they still can provide insight into the academic reference process and how best to prepare librarians to meet it.

The Eisenberg-Berkowitz IPS model also provides a useful checklist as reference librarians address specific patron requests. Librarians can use the model to ascertain where the student is in the research process, advise accordingly, and verify that all relevant steps are covered. This is particularly useful for novice reference librarians who may feel overwhelmed by the collection itself and the vast range of questions confronting them: it provides an easily accessible "handle" or entry point.

Using the IPS model also can prompt librarians to think about their own natural tendencies in approaching reference work. If the researcher's experiences are any indication, using the model to analyze reference encounters may raise

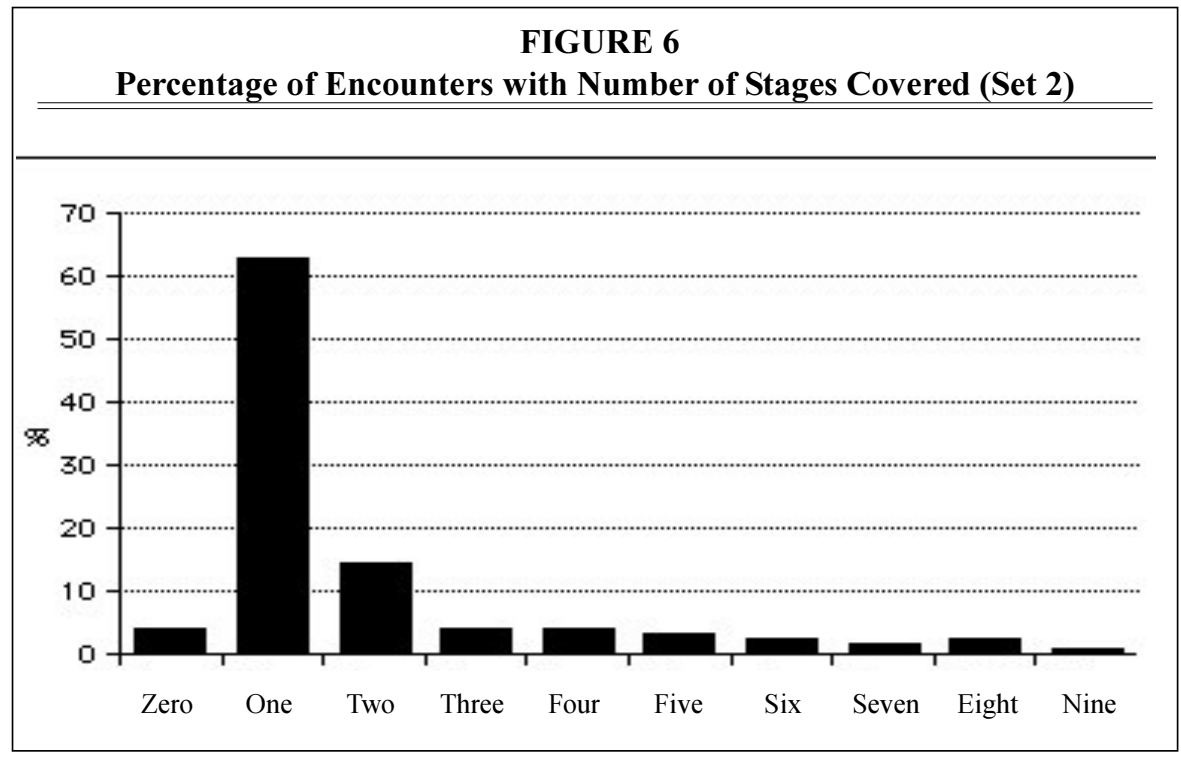


awareness of which stages come naturally and which ones may need more attention, not necessarily in specific encounters but, rather, in general.

Awareness of the IPS model can help librarians keep the reference process on track. For example, when a system or hardware problem impedes a patron, the natural tendency is to try to solve it. Sometimes, however, it is useful (indeed necessary) to step back and look at the problem in IPS terms. For example, if a printer is malfunctioning, the patron cannot extract information (step 4.2). If the printer cannot be fixed quickly, the real solution from the patron's point of view is not to fuss with the printer but, rather, to redirect the output to a working printer or, if that is not possible, to reenter the search on a properly functioning workstation and print the results there. Analyzing the problem in IPS terms helps refocus the effort onto the patron's actual need.

One unanticipated implication of this research applies to an aspect of campus planning. As colleges and universities begin to accept information problemsolving models such as the EisenbergBerkowitz model, they are taking a closer look at how to promote core information competencies on their campuses. But the current research indicates that one of the areas normally thought to promote these competencies-the library-is, in fact, not providing resources for major stages of the model: the stages having to do with creation and evaluation of the product.

Synthesis and product evaluation will not occur in the library reference workstation area until "synthesis tools" (word processing, spreadsheet, database, graphics, or citation management software, laser quality printers, and so on) are available there in addition to the more typical library databases. Adding tools such as these to the reference area toolbox is controversial because they add greatly to the support burden.

However, if schools are going to combine their library and computing center, as many are, this is a good reason to do so: to create one place on campus where students can work through all the information problem-solving steps including brainstorming, locating, using, evaluating, and synthesizing information. Instead of a reference area that focuses only on database searches, schools who wish to emphasize all aspects of information literacy may choose to create an information commons that includes tools to create printed or electronic information products.

Such a facility would need to be staffed by people who are familiar with all the IPS steps and can support not just database searches, but also other aspects of product synthesis, including applications software, multimedia production, and effective writing. This may mean pulling together services that ordinarily may reside in different locations such as the library reference area, the writing center, the computer center, and so on. ${ }^{17}$

Administrative arguments for combining libraries, computing centers, or other campus services often are based on budgetary or logistical considerations: consolidation saves money and space. In practice, however, these savings may be difficult to realize. The current study, although preliminary, indicates that there may be a stronger rationale for collaboration or consolidation, a rationale based on providing better services to students.

\section{Future Research}

The findings of this study suggest several promising avenues for future research. One obvious follow-up would be to compare these findings with those of other academic environments, including different kinds of schools.

Moreover, these findings could be enhanced by combining the observational techniques used here with interviews or other substantive discussion. Follow-up interviews with patrons would provide qualitative data allowing a more indepth understanding of their perceptions of the reference encounters. For example, it would be particularly interesting to de- 
termine whether the patrons were aware of going through a series of stages during their work.

In schools with active information literacy programs, the techniques described here could be used as part of a pre- and posttest to help assess the effectiveness of the programs. Conversely, interview techniques could be used to determine whether patrons already had had any information literacy instruction.

Finally, given the implications for campus planning discussed above, comparable data from different service points on the same campus would provide insight into whether and how students request and receive aid throughout the IPS process. In schools where computing support is separate from library support, computing help desks probably field many questions related to the synthesis stage, as students rely on application software to produce papers, slides, and so on, just as campus writing centers may focus on task definition, synthesis, and evaluation as they help students tackle major writing assignments. In schools where computing and library support have been combined, the research techniques described here may help evaluate the effectiveness of the combined service points in addressing the full spectrum of information problem-solving tasks.

\section{Notes}

1. Richard L. Derr, “Questions: Definitions, Structure, and Classification," RQ 24 (winter 1984): 186-190.

2. Richard E. Bopp, "History and Varieties of Reference Services," in Reference and Information Services: An Introduction, ed. Richard E. Bopp and Linda C. Smith (Englewood CO: Libraries Unlimited, Inc., 1995).

3. F. Wilfrid Lancaster and Amy J. Warner, "Some Basics of Information Retrieval," chap. 1 in Information Retrieval Today (Arlington, VA: Information Resources Pr., 1993).

4. Diane M. Brown, "Telephone Reference Questions: A Characterization by Subject, Answer Format, and Level of Complexity," RQ 24 (spring 1985): 290-303.

5. Thomas Childers, Cynthia Lopata, and Brian Stafford, "Measuring the Difficulty of Reference Questions," RQ 31 (winter 1991): 237-43.

6. Ellen D. Sutton and Leslie E. Holt, "The Reference Interview," in Reference and Information Services: An introduction, ed. Richard E. Bopp and Linda C. Smith (Englewood CO.: Libraries Unlimited, Inc., 1995).

7. Carol Collier Kuhlthau, "Developing a Model of the Library Search Process: Cognitive and Affective Aspects," RQ 28 (winter 1988): 232-42.

8. - Seeking Meaning: A Process Approach to Library and Information Services (Norwood, N.J.: Ablex, 1993).

9. - "Impact of the Information Search Process Model on Library Services," RQ 34 (fall 1994): 21-26.

10. Ibid., 23.

11. Lynn Kennedy, Charles Cole, and Susan Carter, "Connecting Online Search Strategies and Information Needs: A User-centered, Focus-labeling Approach," RQ 36 (summer 1997): 562-68, and "The Optimization of Online Searches through the Labeling of a Dynamic, Situation-dependent Information Need: The Reference Interview and Online Searching for Undergraduates Doing a Social-Science Assignment," Information Processing and Management 32 (Nov. 1996): 709-17.

12. Michael B. Eisenberg and Robert E. Berkowitz, Information Problem-solving: The Big Six Skills Approach to Library \& Information Skills Instruction (Greenwich, CT.: Ablex, 1990).

13. Mary Warner, "Western Carolina University's Model of Integrating Information Literacy: Partnering the First-Year Composition Instructor, Students, and a Personal Librarian," paper presented at the annual meeting of the Conference on College Composition and Communication, Chicago, Apr. 1-4, 1998.

14. Eisenberg, personal communication, Apr. 20, 1998.

15. Eisenberg and Berkowitz, Information Problem-solving.

16. Michael B. Eisenberg and Doug Johnson, Computer Skills for Information Problem-solving: Learning and Teaching Technology in Context (Syracuse, N.Y.: ERIC Clearinghouse on Information and Technology, 1996). ERIC ED 392463. 
17. For a more extensive discussion of integrating research and technology support in libraries, see Chris Ferguson, "'Shaking the Conceptual Foundations,' Too: Integrating Research and Technology Support for the Next Generation of Information Service," College \& Research Libraries 61 (July 2000): 300-311. 